\title{
The Place of Inductive Reasoning in Navya-Nyaya Logic
}

\section{Swami Agehananda Bharati}

At the outset, it will perhaps be convenient if I give a brief historical outline of the school of logic which is the subject of my paper.

Navya-Nyaya means literally 'the new logic', but of course it is a term indicating the continuation of a parampara, a tradition, without which there is hardly anything worthwhile in India. It continues, or to be more precise, it reforms the prachina or ancient Nyaya; it is the name given to a new phase in the development of Brahmin logic, j. e. the phase inaugurated by the Nayayikas' anxiety about and their vindication in face of Sriharsha's ingenious attack, to which my paper will briefly refer.

The Nyaya school of logic is the only school of logic in the Brahmin tradition, and it stands usually as the first among the six classical philosophical systems. This does not indicate any supremacy vis-a-vis the other systems, but it certainly does indicate its methodical importance: there has been no logical argument in India, which did not presuppose knowledge of Nyaya, if not as a total system of thought, at least as a basis for dialectical skill, discipline, and method.

The Nyaya-sutras, ascribed to a mythical seer Gautama, belong to the category of shastra, like the Brahmasutras or the shrautasutras. They are certainly very oldthe majority of western scholars places them about 200 years earlier than the Buddha, Indian scholars would add another two or three centuries to its age, thus making it contemporaneous with the oldest Upanishads, the Chandogya and Brhadaranyaka.

The Navya-Nyaya tradition commenced in Mithila, not too far from the Buddhist university of Nalanda, on the northern side of the river. The competition between the three centres-Nalanda of the Buddhists, Mithila of the Brahmins, and Vaishali of the Jains was.keen and vivacious for centuries, and taken up by some lamas in Tibet.

Today, the three institutes have been revivified through the efforts of the Indian educational and cultural authorities, and have began to flourish-Japanese scholars 
have begun and are working at those places along with researchers from other Asian lands.

Due to certain intrigues within the folds of the Mithila scholars of the 16th and 17th centuries, the centre was shifted rather far away to the east, into Navadvip in Bengal, and ever since the school has been known as the Navadvip school of logic.

In spite of the fact that the revolutionary character of the reformed logic was recognized by logicians all over lndia, its following remained somewhat parochial, and its technical innovations are hardly used outside the fold of the Navadvip-cumMithila pundits. Also, the adherence of the Hindu pundit to some Vedantic school in the final analysis, even where he is a logician, makes one feel that there is scarcely any interest in logic for its own, purely scholastic sake. Let me now proceed to my subject proper-

The main purpose of this paper is to evaluate some of the salient points of the new Nyaya literature and juxtapose them with the relevant themes in contemporary western logic. I have selected the place of induction, this being a comparatively succinct topic falling well within our comparative scope-and like all other subjects, logic should be viewed from the standpoint of latest research. It goes without saying that real advance has been made in this subject, in western countries, especially Anglo-Saxon, in the last 50 years-applying its results as criteria of comparative examination is a fair matter, although Indian logicians do not seem to be too enthusiastic yet about the idea.

You all know how reformed Nyaya arose through Gangeshacharya's magnificent critique of Sriharsha's Khandanakhandakhadya, which in its turn had been aimed at refuting Udayana's logical optimism as voiced in the latter's Nyayakusumanjali. From a neutral point of survey, the laurel should certainly go to Sriharsha in the total frame-not so much for his acute criticism as for his philosophical impartialityfor he probably was the first Indian thinker who philosophized for the sake of discursive philosophy, and showed that this is a separate, intellectual enterprise with no bearing whatever, negative or positive, on scholastic, theologica1, and denominational loyalties.

The most exciting thing about Nyaya seems to me their perpetual emphasis and elaboration of their ancient axiom that reason is no instrument of knowledge at all-that it is just a kind of accessory, its function being purely heuristic. Udayana's term for inductive reasoning is 'aharyaropa', which Prof. S. Bagchi interprets well 
enough as 'imaginary assumption'. Udayana holds that valid induction has somekind of cognitive, but an indefinite status. Udayana it was, I believe, introduced the term 'tarkayami...' into logical language, and that exactly corresponds to our contemporary use of the Cartesian stock-in-trade 'specie argumenti...' 'for argument's sake'.

Modern logicians get very nervous about the jejuneness of the Nayayikas' paradigmata- somehow, the smoke and the fire and the mountain and the lake have shown a tough life similar to that of the snake and the rope in metaphysical speculation,- but the cause for greater uneasiness is that they seem to illustrate the basic idea that there are only subject-predicate propositions; and it is a most certain that Indian logicians, with the exception of the Buddhists, shared this shortcoming with Aristotle's logic. However, it seems to me that primitive syllogistic inference was not the chief interest of the new Nayayikas. Rather, their chief concern was the ascription of its particular logical status to each proposition.

Udayana and most of his fellow-logicians thought that hypothetical inference and judgment constituted the essence of inductive reasoning- which is true in a way-and in the way of traditional formal logicians of the West, they also feel doubts about the logical status and about the formal validity of inductive reasoning. Navya Nyaya realized that the inclusion of hypothetical judgment into the category of formally valid judgments was but a linguistic legerdemain, and that their enumeration along with categorical judgments was logically unjustifiable.

Now of course the fact is that categorical judgments of the universal type are hypothetical in the last analysis-a discovery of modern logic: we cannot really be angry with Udayana and Gangesha for not having read Russell. The important achievement of the Indian logicians of the reformed Nyaya was that they were keenly aware of the pitfalls of language, and of the necessity of linguistic analysis detached from grammatical ruling.

Coming back to our problem-the place of induction in Navya-Nyaya, we see how they have improved upon the older school in the definitive distinction between hypothetica1 judgment and error-which as you know had been highly unsatisfactory in old Nyaya. True, the phenomenon of 'aropa' is there in both-but I think it is a psychological rather than a logical notion; the erring person is not aware (and this is a psychological event) of attributing an invalid predicate to a subject whereas in the case of 'aharyaropa' the ascription of an invalid, or uncertain predicate to the subject is conscious. 
The definition of this 'assumption' initiated through the idiom 'tarkayami' is as. acute as could be-

sva-viruddha-dharma-dharmita-avacchedakam

sva-prakarakam-jnanam-aharyam,

e. g. a judgment which has an attribute as its predicate, whose contradiction is known as a true determination of the strbject:

Our new logicians were aware that reasoning involved complex judgments, but the idea that a complex judgment was something qualitatively different from a simple or a single judgment does not seem to have occurred to them; references to the complexity of judgments (such words as vikirna, vistrita a. o. are used) are no doubt frequent, but their occurrence is sporadic and unsystematized. I said above that there was no knowledge in Navya-Nyaya about the numerous logical forms of propositions. I believe that had the idea of vikirania or vistara been systematically elaborated or even just arranged, Indian logic might well have presaged the dicta of contemporary western logic by three centuries. Their tools were as acute as those of modern logic are, though they were not so sophisticated-and from a modern viewpoint, the lack of sophistication is certainly held against them, just as it is held against Aristotelian logic.

In merit, I believe the Navya-Nyaya's views about the value of inductive reasoning lies somewhere between Mill and modern logic-I mean they argued better than Mill, but not quite so well as functional logic today-and the reason for the latter fact seems to me that the Indian logicians were hampered by the habit of seeking triviality of the paradigmata they insisted to use without alteration through the ages. I cannot work out this idea in this frame, but there seem to be good reasons to hold that naive instances for logical exemplification mar progressive argument, and that the famous 'Socrates is a philosopher' has been accountable for much unnecessary retardation in western thought. The Indian logician will have to come away from the lake, the mountain, the fire, and the universally concomitant smokeI am quite radical about that.

Probability, which has been one of the most controversial themes of late in western thought, does not seem to have been allotted a status separate from that of hypothetical assertion-both the concepts appear to have been subsumed under the term 'sambhavana.' Udayana assigns almost complete force to it as a proof of noncontradiction, in which he would come close to Prof. Kneale, one of the finest. 
exponents of probability theory today.

There are a few works in Indian thought that have had a revolutionary character much in the way of the Kantian Critiques. Gangeshacharya's Nyayatattvachintamani is one of them. His treatment of induction (vyaptigraha) is unique. $\mathrm{He}$ shows its main function to be the reductio-ad-absurdum of the wrong one of two alternative propositions. Much like Stebbing and Russell, he teaches a plurality of causes in any causal nexus, where the older school believed in a one-one relation of cause and effect.

More recent Nayayikas, like Mathuranatha taught that knowledge gained by induction was of a perceptual rather than of an inferential order. In a way, the Indian controversy between those who give an inferential ticket to inductive argument and those (fewer in number and importance) who concede a perceptual character to it, is analogous to the contemporary dispute about logical constructions. It now remains to be seen whether the new Nayayikas' 'trees' and 'lakes' and their 'smoke' were meant by them to convey symbols for hard data or sensa, or whether they already are the Russellian 'constructions.

Such interest must open an entirely fresh field of comparative study and fieldwork-it will require students who are equally conversant with Sanskrit logic and with contemporary western logic-a case for truly international scholastic cooperation.
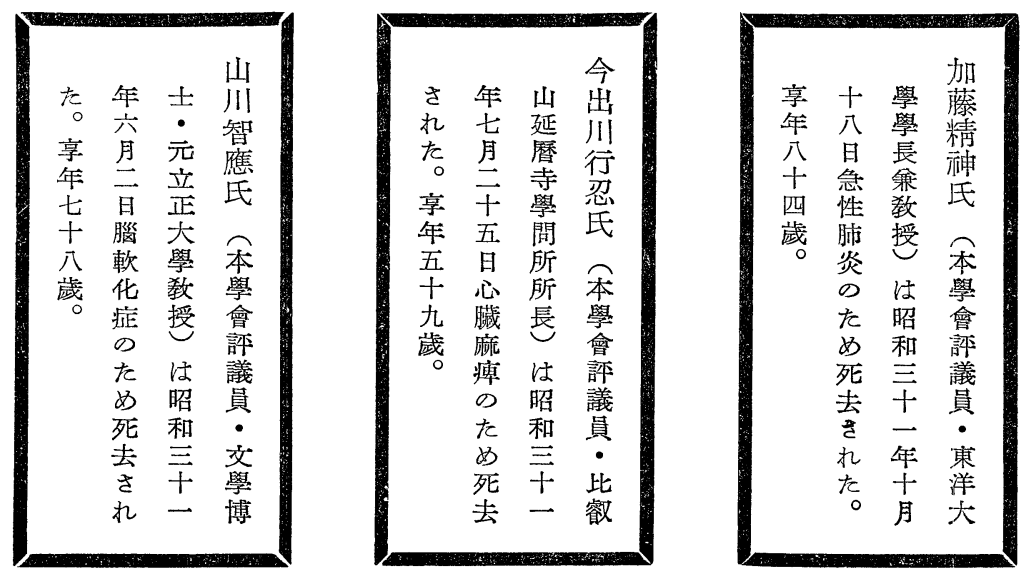